\title{
A study of assessments of camptocormia
}

\author{
M De Sèze*, E Guillaud, L Slugatz, JR Cazalets \\ From 9th International Conference on Conservative Management of Spinal Deformities - SOSORT 2012 \\ Annual Meeting \\ Milan, Italy. 10-12 May 2012
}

\section{Introduction}

Camptocormia (or bent spine syndrome) is defined as abnormal posture, with marked flexion of the thoracolumbar spine, increasing during walking, and disappearing in the supine position. This definition is not so clear, and indeed, there are no consensus criteria for diagnosing camptocormia. Consequently, the prevalence of camptocormia is difficult to determine. More often, the diagnosis is made by subjectively assessing the patient's posture, but this approach is no more satisfying, because the camptocormia can be overestimated or underestimated.

\section{Aim}

The aim of our study was to investigate different methods for assessing camptocormia.

\section{Material and methods}

Camptocormia was subjectively defined as forward flexion of the thoracolumbar spine that disappeared in the recumbent position. Patients were excluded if they were not able to walk more than ten meters without human or technical help. All the includable patients were convoked one afternoon for clinical, radiological, and kinematical assessments for the following 30 days. Parameters: Two visual radiological and kinematic markers were initially positioned on the patients. They were left on the skin during all the assessment, in order to be able to relay clinical, radiological and kinematical conditions. One marker was positioned in regard to the spinous process of $\mathrm{C}$, and the other marker was positioned in the middle of the segment relaying the two Michaëlis fovea, in order to project horizontally to S1. Sagittal inclinations were valued by the $\mathrm{C} 7$ arrow, defined as the distance from the C7 marker to a plumb line of the S1 marker.

\section{Results}

Forty three patients ( 28 females and 15 males; $69 \pm 10$ years) were included in the study. The mean increase of the $C 7$ arrow during walking was $64.2 \pm 45.6 \mathrm{~mm}$ for the patients presenting an initial $\mathrm{C} 7$ arrow superior or equal to $200 \mathrm{~mm}$, and was $31.6 \pm 30.1 \mathrm{~mm}$ for the patients presenting an initial C7 arrow inferior to $200 \mathrm{~mm}$, ( $\mathrm{p}=$ 0.0040 ). For each static condition, we could define a similar threshold separating the patients in two groups of and increasing $\mathrm{C} 7$ arrow during walking.

\section{Conclusion}

These results open perspectives in order to propose objective definition of camptocormia.

Published: 3 June 2013

\section{References}

1. de Sèze M, Lavignolle B, Mazaux J, Schaeverbeke T, Tison F, Vital : Déviations rachidiennes et maladie de Parkinson. Revue de Rhumatisme 2004, 290-296.

2. de Seze MP, Creuze A, de Seze M, Mazaux JM: An orthosis and physiotherapy programme for camptocormia: a prospective case study. J Rehabil Med 2008, 40(9):761-765.

3. Doherty KM, van de Warrenburg BP, Peralta MC, Silveira-Moriyama L, Azulay JP, Gershanik OS, Bloem BR: Postural deformities in Parkinson's disease. Lancet Neurol 10(6):538-549.

4. Mac-Thiong JM, Transfeldt EE, Mehbod AA, Perra JH, Denis F, Garvey TA, Lonstein JE, Wu C, Dorman CW, Winter RB: Can C7 plumbline and gravity line predict health related quality of life in adult scoliosis? Spine (Phila Pa 1976) 2009, 34(15):E519-527.

\section{doi:10.1186/1748-7161-8-S1-031}

Cite this article as: De Sèze et al.: A study of assessments of camptocormia. Scoliosis 2013 8(Suppl 1):O31.

$\overline{\mathrm{CHU}}$ de Bordeaux, Université Bordeaux Ségalen, Bordeaux, France

(c) 2013 De Sèze et al; licensee BioMed Central Ltd. This is an Open Access article distributed under the terms of the Creative Commons 